\title{
Spatial and temporal variation of anthropogenic black carbon emissions in China for the period 1980-2009
}

\author{
Y. Qin and S. D. Xie \\ College of environmental sciences \& engineering, State Key Joint Laboratory of Environmental Simulation and Pollution \\ Control, Peking University, Beijing, China
}

Correspondence to: S. D.Xie (sdxie@pku.edu.cn)

Received: 23 October 2011 - Published in Atmos. Chem. Phys. Discuss.: 13 December 2011

Revised: 7 May 2012 - Accepted: 9 May 2012 - Published: 1 June 2012

\begin{abstract}
Multi-year inventories of anthropogenic black carbon emissions, including both fuel consumption and biomass open burning, at a high spatial resolution of $0.25^{\circ} \times 0.25^{\circ}$ have been constructed in China using GIS methodology for the period 1980-2009, based on official statistical data and time-varying emission factors. Results show that black carbon emissions increased from $0.87 \mathrm{Tg}$ in 1980 to $1.88 \mathrm{Tg}$ in 2009 with a peak in about 1995 , and had been continually increasing in the first decade of the 21 century. Residential contribution to the total $\mathrm{BC}$ emissions declined from $82.03 \%$ in 1980 to $42.33 \%$ in 2009 at a continuous diminishing trend, but had always been the dominant contributor in China. While contributions from industry and transportation sectors had increased notably. BC emissions were mainly concentrated in the central eastern districts, the three northeastern provinces and the Sichuan Basin, covering $22.30 \%$ of China's territory, but were responsible for $43.02 \%, 50.47 \%$, $50.69 \%$ and $54.30 \%$ of the national black carbon emissions in 1985, 1995, 2005 and 2009, respectively. Besides, China made up 70\%-85\% of BC emissions in East Asia, half of the emissions in Asia, and accounted for averagely $18.97 \%$ of the global BC emissions during the estimation period.
\end{abstract}

\section{Introduction}

Black carbon (BC) emissions have caught extensive concern among the scientific community as a major contributor to global warming and a well established health hazard (Zhang et al., 2010). Even though climate change and air pollution are closely linked, they have been addressed separately in applied scientific research and political negotiations previously
(Swart et al., 2004). Recently, more integrated studies have been conducted to study the linkage between climate change and air pollution (Swart et al., 2004; Aunan et al., 2006; Rypdal et al., 2009; Kopp and Mauzerall, 2010). Therefore, well-known air pollutants such as BC, which are also shortlived climate forcing agents, are attracting increasing scientific interests, considering that their reduction can have both climate and health benefits, especially in developing countries with large $\mathrm{BC}$ emissions and relatively low abatement costs (Rypdal et al., 2009). Before 1950, developed countries such as the USA and the UK were the major sources of $\mathrm{BC}$ emissions; however, developing countries like India and China have taken their position and become the substantial contributors thereafter (Novakov et al., 2003; Junker and Liousse, 2008). China is thought to be responsible for $24 \%$ of global BC aerosol burden (Bond et al., 2004). It is estimated that exposure to $\mathrm{SO}_{4}^{2-}$, $\mathrm{OC}$ and $\mathrm{BC}$ aerosols of Chinese origin resulted in approximately 500000 premature deaths in China and 11000 in Korea and Japan in 2000 (Saikawa et al, 2009). In addition, global climate modeling has indicated that BC can affect large-scale circulation and the hydrologic cycle, and may be associated with increased floods in southern China and increased drought in northern China (Menon et al., 2002). To scientifically understand the contribution of Chinese BC emissions to both regional and global air quality, premature mortality and climate effects, and to build the scientific foundation for bringing out global cost-effective measures to achieve simultaneous control of climate change and air pollution, it is significant to develop complete and reliable tempo-spatial Chinese $\mathrm{BC}$ emission inventories.

Chinese black carbon emission inventories have been addressed previously by pioneering scholars, markedly Streets 
et al. (2001), Streets et al. (2003a), Novakov et al. (2003), Bond et al. (2004), Ito and Penner (2005), Cao et al. (2006), Ohara et al. (2007), Zhang et al. (2007, 2009), Junker and Liousse (2008). However, following problems hindered the accuracy of prior results, and consequently, their application to national policy. First, significant differences were found among the results due to activity data inaccuracy and local emission factors (EFs) deficiency. For instance, energy data used by Streets et al. (2001, 2003a) were extracted from the RAINS-Asia numerical model and predicted energy consumption by Sinton et al. (2000), which were highly uncertain. Zhang et al. (2009) built up emission inventory in 2006 based on a mixture of trend extrapolations from 2004/2005 and actual 2006 data due to data deficiency, which cannot accurately quantify the actual Chinese BC emissions in 2006. Besides, more domestic experiments studying local BC emission factors were conducted in recent two years (Chen et al., 2009; Li et al., 2009; Shen et al., 2010). However, because of relatively early publication of previous emission results, almost none have applied these latest updated local EFs. Second, Chinese BC emissions in a certain year were studied, but annual variations with a long time scale were rarely addressed (Streets et al., 2001, 2003a; Cao et al. 2006; Zhang et al., 2007, 2009). Only recently, Lu et al. (2011) constructed the Chinese BC emission inventory from 1996 to 2010 with activity rates extrapolated from 2008 to 2010 based on national fast-track statistics, but still without providing the historical and current $\mathrm{BC}$ emissions using a consistent methodology. Third, few existing historical emission inventories at the global or Asia scale, from which Chinese $\mathrm{BC}$ emissions can be extracted, are either incomplete or highly uncertain because of the method applied or constant EFs used over the years. For example, Ohara et al. (2007), and Junker and Liousse (2008) incorporated historical Chinese BC emissions for 1980-2020 and 1860-1997 in their Asian and global emission inventories, respectively, without considering emissions from biomass open burning. Novakov et al. (2003) calculated global BC emissions from fossil fuel combustion in six regions, including China, from 1875 to 2000 , based on global $\mathrm{CO}_{2}$ emission data and the $\mathrm{BC} / \mathrm{CO}_{2}$ ratios available in the UK, which were highly variable and limited. Ito and Penner (2005) established the global historical carbonaceous aerosol emission inventories, including all anthropogenic sources, for the period 1870-2000, from which Chinese BC emissions can be extracted. However, they did not take the changes of emission factors, except those for diesel burning, during the period 1974-1996 into account, which were considerable due to fast technology development in the late 20th century.

In this case, Chinese government forwarded a National Program on Key Basic Research Project (973 Program) to address these issues, and this study, as a component of the program, focused on establishing historical black carbon emission inventories in China using a consistent methodology. Emission inventories covering fossil fuel and biofuel com- bustion, as well as biomass open burning, for the period 1980-2009 which were actually represented by the years of 1980, and consecutive $25 \mathrm{yr}$ from 1985 to 2009 were built up based on published official statistical data at county level and time-varying domestic emission factors, which were further gridded at a high resolution of $0.25^{\circ} \times 0.25^{\circ}$ by GIS Methodology. Annual variation of national $\mathrm{BC}$ emissions during the past thirty years was discussed, temporal variation of spatial distribution from 1980 to 2009 was studied, and historical changing trends of Chinese contributions to emissions at global, Asia and East Asia scale were quantified.

\section{Methodology}

\subsection{Emissions estimation}

Detailed emission calculations were aggregated into five sources of residential, industry, power generation and heating, biomass open burning, and transportation. Vehicular emissions were estimated by the population, mileage traveled and emission factors for each vehicle category; emissions from biomass open burning were estimated by biomass burned, burning efficiency and the corresponding EFs. Emission estimation for other sources was based on annual average rates of emission related activities, emission factors, and removal efficiency for each source. Detailed methodology was referred to Qin and Xie (2011a). Total BC emissions were calculated by Eq. (1).

$Q_{m, n}=\sum\left(\mathrm{EF}_{i, f, m, n} \times \mathrm{VP}_{i, f, m, n} \times \mathrm{VMT}_{i, n}\right)$

$+\sum\left(\mathrm{EF}_{j} \times B_{j, m, n} \times \delta_{j}\right)+\sum \mathrm{EF}_{k, f, n} \times A_{k, f, m, n} \times\left(1-\eta_{k, n}\right)$ where: $Q_{m, n}$ is the total BC emission in province $m$ in year $n ; m$ is the province, $n$ is the year, $f$ is fuel type; $i, j$ and $k$ indicate vehicle type, biomass type and other sources excluding biomass open burning and vehicles, respectively; $\mathrm{EF}$ is BC emission factor; VP is the vehicle population; VMT is the annual vehicle mileage; $B$ is the biomass open burning amount; $\delta$ is the burning efficiency; $A$ represents fuel consumption, and $\eta$ is the removal efficiency.

\subsection{Emission allocation}

Provincial BC emissions were first calculated, followed by allocation to the county level based on proxy variables, as those in Qin and Xie (2011a), using equation 2. County-level $\mathrm{BC}$ emission inventories were further converted to grids at a resolution of $0.25^{\circ} \times 0.25^{\circ}$.

$Q_{c, m, i, n}=\frac{P_{c, m, n}}{\sum_{c=1} P_{c, m, n}} \times Q_{m, i, n}$

where: $Q_{c, m, i, n}$ is the emission of source $i$ in county c of province m in year $n, Q_{m, i, n}$ is the BC emission from source $i$ in province $m$ in year $n$, and $P_{c, m, n}$ is the proxy variable in county $c$ of province $m$ in year $n$. 
Table 1. Time tables for vehicle-emission-regulations implementation in China.

\begin{tabular}{lcccc}
\hline & Euro I & Euro II & Euro III & Euro IV \\
\hline Beijing & 1999 & 2002 & 2005 & 2008 \\
Shanghai & 1999 & $2005^{\mathrm{a}}$ & $2008^{\mathrm{b}}$ & 2009 \\
National & 2001 & $2005^{\mathrm{a}}$ & $2008^{\mathrm{b}}$ & 2010 \\
\hline
\end{tabular}

a the actual implementation time is June, 2004;

$\mathrm{b}$ the actual implementation time is June, 2007.

\section{Compilation of emission factors and activity data}

\subsection{Transportation}

Transportation includes subsectors of aviation and vehicles. Kerosene consumed by aviation was obtained from China Civil Aviation Yearbooks. Vehicles were classified into ten categories of gasoline buses and coaches, diesel buses and coaches, gasoline passenger cars, diesel passenger cars, gasoline heavy-duty vehicles, diesel heavy-duty vehicles, gasoline other-duty vehicles, diesel other-duty vehicles, twostroke motorcycles and four-stroke motorcycles. New vehicles with advanced emission-control technologies have been quickly introduced in the past ten years (Table 1), thus we assume EFs for new cars introduced after the implementation of a severer emission regulation should fit the higher standard.

$\mathrm{EF}_{\mathrm{BC}}$ for each vehicle type fueled with gasoline or diesel under different emission regulations were developed based on $\mathrm{EF}_{\mathrm{PM}}$ from COPERT model (Cai and Xie, 2007), as presented in Table 2, and $F_{\text {fine }}$ and $F_{\mathrm{BC}}$ in the transport sector (Bond et al., 2004), the same method in Qin and Xie (2011a).

Provincial population of each vehicle type was obtained from China Automotive Industry Yearbooks (China Automobile Industry Association, 1985-2010). Statistical data of newly-introduced vehicles for each category are only available for 2002-2009, thus the average introducing rate for each vehicle type during this period was used to estimate newly-introduced vehicles in other years, respectively. Besides, the proportion of diesel vehicles in each vehicle category was assumed to be approximately equal to that of the yearly automobile sales data of specific vehicle category classified by fuel type, which was obtained from China Automarket Yearbooks.

The annual total mileage of different vehicle types was determined by relevant literature sources and reasonable hypotheses. Buses and coaches are responsible for the majority of national passenger turnover in China. The mileage of buses and coaches was calculated by equation 3 (Qin and Xie, 2011a).

$\mathrm{VMT}_{b, n}=Q_{b, n} /\left(\alpha_{b, n} \times \mathrm{VP}_{b, n} \times T_{b}\right)$

where: $\mathrm{VMT}_{b, n}$ is the mileage of buses and coaches in year $n, Q_{b, n}$ is the passenger turnover accomplished in year $n$, $\alpha_{b, n}$ is the actual loading rate of buses and coaches in year $n$, $\mathrm{VP}_{b, n}$ is the population of buses and coaches in year $n$, and $T_{b}$ is the average number of seats on buses and coaches.

National cargo turnover is accomplished by both heavy duty vehicles and other-duty vehicles, whose respective contributions were assumed to be positively correlated with their population and the average tonnage carried, as shown in Eq. (4). The mileage of heavy duty vehicles (other-duty vehicles) was calculated by Eq. (5).

$$
Q_{p, n}=Q_{n} \times \frac{\mathrm{VP}_{p, n} \times T_{p}}{\sum_{1}^{p} \mathrm{VP}_{p, n} \times T_{p}}
$$

$\mathrm{VMT}_{p, n+1}=\frac{Q_{p, n+1} \times \mathrm{VP}_{p, n} \times \beta_{p, n}}{\operatorname{VP}_{p, n+1} \times \beta_{p, n+1} \times Q_{p, n}} \times \mathrm{VMT}_{p, n}$

where: $Q_{n}$ represents the national cargo turnover in year $n$; $Q_{p, n}$ and $Q_{p, n+1}$ represent the cargo turnover accomplished by vehicle type $p$ (heavy duty vehicles or other-duty vehicles) in year $n$ and year $n+1$, respectively; $\mathrm{VP}_{p, n}$ represents the population of vehicle type $p$ in year $n ; T_{p}$ represents the average tonnage carried by vehicle type $p ; \beta_{p, n}$ represents the actual loading rate of vehicle $p$ in year $n ; \mathrm{VMT}_{p, n}$ and $\mathrm{VMT}_{p, n+1}$ represent the annual average mileage of vehicle $p$ in year $n$ and year $n+1$, respectively .

Lacking of appropriate statistical data to infer the mileage of passenger cars and motorcycles, they were obtained from summarized literatures survey (Cai and Xie, 2007; Bo et al., 2008). Mileages of different vehicle types from 2000-2009 were shown in Table 3.

\subsection{Biomass open burning}

Emission factors for open burning of agricultural waste were obtained from local experiments (Cao et al., 2007), and EFs for forest and grassland fire were gained from reported literatures (Turn et al., 1997; Streets et al., 2003b; Reddy and Venkataraman, 2002; Streets et al., 2003a; Lavoué et al., 2000). BC emission factors for biomass open burning do not change during the estimation period, as the open burning process never experienced great revolution, as presented in Table 4 .

Total crop yields in China increased from 335.32 million tons in 1980 to 691.89 million tons in 2009, doubled during the period. Provincial crop residues production was calculated according to the crop yields and respective productionto-residue ratio of specific crop type (Lal, 2005). National crop residues showed a continuous growth trend during this period, with an annual average increasing rate of $3.65 \%$, as shown in Fig. 1. Cao et al. (2006) deduced that crop straw openly burnt is proportional to peasants' income level, with a correlation coefficient of 0.81 . Region-specific burning ratio in 2006 was obtained from Wang and Zhang (2008), and open burning ratios in other years were deduced according 
Table 2. Black carbon emission factors for specific vehicle type under different regulations in China, based on COPERT modeled results.

\begin{tabular}{lccccc}
\hline Vehicle types & Euro 0 & Euro I & Euro II & Euro III & Euro IV \\
\hline Gasoline Buses and Coaches & 0.0208 & 0.0208 & 0.0208 & 0.0208 & 0.0208 \\
Diesel Buses and Coaches & 0.6811 & 0.3406 & 0.1703 & 0.1703 & 0.0568 \\
Gasoline Passenger cars & 0.0058 & 0.0058 & 0.0058 & 0.0058 & 0.0058 \\
Diesel Passenger cars & 0.2838 & 0.0568 & 0.0568 & 0.0454 & 0.0454 \\
Gasoline Heavy-duty vans & 0.0208 & 0.0208 & 0.0208 & 0.0208 & 0.0208 \\
Diesel Heavy-duty vans & 0.5108 & 0.3406 & 0.1703 & 0.1703 & 0.0568 \\
Gasoline Other-duty vans & 0.0116 & 0.0116 & 0.0116 & 0.0116 & 0.0116 \\
Diesel Other-duty vans & 0.5331 & 0.2228 & 0.2228 & 0.1928 & 0.0982 \\
Two-stroke Motorcycles & 0.0095 & 0.0048 & 0.0024 & 0.0010 & 0.0010 \\
Four-stroke Motorcycles & 0.0014 & 0.0014 & 0.0005 & 0.0005 & 0.0005 \\
\hline
\end{tabular}

Table 3. Vehicle mileage travelled $(10000 \mathrm{~km})$ of each vehicle category from 2000 to 2009.

\begin{tabular}{lcccccccccc}
\hline Vehicle types & 2000 & 2001 & 2002 & 2003 & 2004 & 2005 & 2006 & 2007 & 2008 & 2009 \\
\hline Buses and Coaches $^{\mathrm{a}}$ & 4.23 & 3.95 & 3.86 & 3.74 & 4.06 & 4.04 & 4.08 & 4.25 & 4.25 & 4.22 \\
Passenger cars $^{\mathrm{b}}$ & 3.75 & 3.80 & 3.85 & 3.90 & 3.95 & 4.00 & 4.00 & 4.00 & 4.00 & 4.00 \\
Heavy-duty vans $^{\mathrm{c}}$ & 5.50 & 5.38 & 6.80 & 6.87 & 7.07 & 7.21 & 7.75 & 8.34 & 8.92 & 9.54 \\
Other-duty vans $^{\mathrm{c}}$ & 3.00 & 2.92 & 3.68 & 3.70 & 3.80 & 3.86 & 4.13 & 4.43 & 4.74 & 5.07 \\
Motorcycles $^{\mathrm{b}}$ & 1.30 & 1.31 & 1.32 & 1.33 & 1.34 & 1.35 & 1.35 & 1.35 & 1.35 & 1.35 \\
\hline
\end{tabular}

a calculated by Eq. (3); ${ }^{\text {b }}$ Cai and Xie (2007); Bo et al. (2008); ${ }^{c}$ calculated by Eqs. (4) and (5)

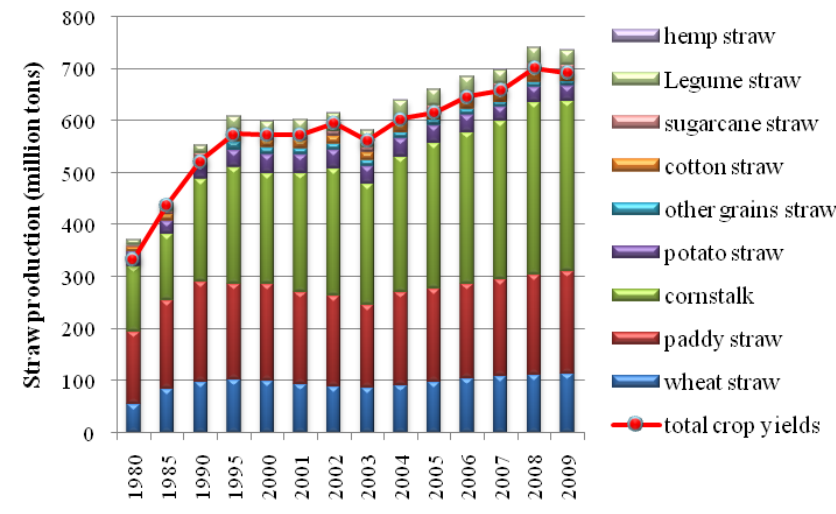

Fig. 1. Crop yields and straw-specific residues production in China from 1980 to 2009.

to the ratios of per capita average peasant income in a certain year to that in 2006, the same method applied in Qin and Xie (2011b). Crop specific burning efficiency was from Turn et al. (1997) and de Zarate et al. (2005), as listed in Table 4. National burning amounts of crop residues increased from $3.73 \mathrm{Tg}$ in 1980 to $203.82 \mathrm{Tg}$ in 2009 , due to the increase of both residues production and burning ratios resulted from the rise of peasant income. Spatially, Shandong, Jiangsu, Hebei and Sichuan provinces had the largest straw burning amounts, while burning amounts in Qinghai, Tianjin, Shanghai, and Beijing districts were the least.

\subsection{Residential}

Residential consumption of fossil fuels and biofuels are contained in this source, which were obtained from China Energy Statistical Yearbooks (National Bureau of Statistics, 1986-2010). Fossil fuels include coal (raw coal and briquettes), oil (gasoline, kerosene, diesel oil and liquefied petroleum gas), and gases (natural gas, coke oven gas, and other coal gas); while biofuels include biogas, firewood, and crop residues used as rural energy. Statistical data of biofuels consumed in the 1980s are missing, thus we assume the annual provincial biogases consumed and the annual provincial ratio of residue biofuels to total crop yields in the 1980s have the same yearly changing trends as those from 1991 to 2009 in each province, respectively.

Emission factors for coal, residue and wood burning were from local measurements (Chen et al., 2005, 2006, 2009; Li et al., 2009; Zhi et al., 2008, 2009; Shen et al., 2010), while EFs for oil and gas burning from Bond et al. (2004), as listed in Table 5. Emission factors in residential sector do not change over time since few, if any, control measures have been taken in this sector during the estimation period.

\subsection{Industry}

The industry source includes both industrial final consumption and industrial processes, with coal being the major energy source. 11.02 billion tons of coal was burned by industry sector in 2005, accounting for $45.69 \%$ of national coal 
Table 4. Black carbon emission factors and burning efficiency for different biomass types in China.

\begin{tabular}{lccccccccc}
\hline Straw type & paddy & wheat & corn & cotton & sugarcane & oil crop & other straw & forest fire & grassland fire \\
\hline EF $\left(\mathrm{g} \mathrm{kg}^{-1}\right)$ & $0.52^{\mathrm{a}}$ & $0.52^{\mathrm{a}}$ & $0.78^{\mathrm{a}}$ & $0.82^{\mathrm{a}}$ & $0.69^{\mathrm{b}}$ & $0.69^{\mathrm{b}}$ & $0.69^{\mathrm{b}}$ & $0.99^{\mathrm{c}}$ & $0.48^{\mathrm{b}}$ \\
Burning efficiency & $0.89^{\mathrm{d}}$ & $0.86^{\mathrm{d}}$ & $0.92^{\mathrm{d}}$ & $0.8^{\mathrm{e}}$ & $0.68^{\mathrm{d}}$ & $0.82^{\mathrm{d}}$ & $0.8^{\mathrm{e}}$ & $0.33^{\mathrm{f}}$ & $0.89^{\mathrm{g}}$ \\
\hline
\end{tabular}

${ }^{a}$ Cao et al. (2007); ${ }^{b}$ Andreae and Merlet (2001); ${ }^{\mathrm{c}}$ The geometric mean of EFs in Turn et al. (1997), Reddy and Venkataraman (2002), Reddy and

Venkataraman (2000) and Andreae and Merlet (2001); ${ }^{\mathrm{d}}$ Turn et al. (1997); ${ }^{\mathrm{e}}$ de Zarate et al. (2005); ${ }^{\mathrm{f}}$ Tian et al. (2003); ${ }^{\mathrm{g}}$ IPCC (2006)

Table 5. Black carbon emission factors for fossil fuels and biofuels burning in residential sector (units: $\mathrm{g} \mathrm{kg}^{-1}$ )

\begin{tabular}{ll}
\hline Fuel type & Emission factor \\
\hline bituminous briquette $^{\mathrm{a}}$ & 0.09 \\
anthracite briquette $^{\mathrm{a}}$ & 0.004 \\
bituminous raw coal $^{\mathrm{a}}$ & 3.05 \\
anthracite raw coal $^{\mathrm{a}}$ & 0.007 \\
gasoline $^{\mathrm{b}}$ & 0.07 \\
Kerosene $^{\mathrm{c}}$ & 0.12 \\
diesel $^{\mathrm{b}}$ & 0.25 \\
LPG $^{\mathrm{c}}$ & 0.068 \\
Gases $^{\mathrm{c}}$ & 0.0001 \\
agriculture waste $^{\mathrm{d}}$ & 0.77 \\
firewood $^{\mathrm{e}}$ & 1.49 \\
\hline
\end{tabular}

${ }^{\text {a }}$ Chen et al. (2009); ${ }^{\text {b }}$ Streets et al. (2001); ${ }^{\text {c }}$ Bond et

al. (2004); ${ }^{\mathrm{d}}$ The geometric mean of EFs in Shen et

al. (2010) and Li et al. (2009) ${ }^{\mathrm{e}} \mathrm{Li}$ et al. (2009)

consumption in that year. Black carbon EFs of indigenous coking were much larger compared with EFs of mechanical coking, and the ratio of coal consumed by mechanical coking to indigenous coking was obtained from the China County Statistical Yearbooks, which varied annually, influencing the net EFs for coking processes.

Net EFs for industrial final consumption change over time with the greater usage of higher performance control devices and improved removal efficiency of all devices. Because China has such a large territory and huge regional development gap, the application ratio and removal efficiency vary significantly across the country. Besides, there are no statistical data regarding the annual national use ratio and removal efficiency, and it is impossible to survey these parameters in each year from 1980 to 2009. Therefore, we have to make a simple assumption which can relatively reflect the changing trends of the national use ratio and removal efficiency in each year, based on the available survey results by Streets et al. (2001). Streets et al. (2001) presented the applying percentages of various control devices and the removal efficiency of all devices in industry sector in China in 1995 and 2020, respectively (Table 6). Assuming the use ratio and removal efficiency changed linearly from 1995 to 2020, and made an extrapolation to 1980 , annual $\mathrm{EF}_{\mathrm{BC}}$ in these sectors can be inferred by Eq. (6) (Qin and Xie, 2011a). This assumption is not an ideal one, but it at least provides the rel- ative changing trends of the national use ratio and removal efficiency, thus it is both feasible and acceptable. Moreover, the uncertainty resulted from the assumed use ratio and removal efficiency was included in the inventory uncertainty analysis.

$\mathrm{EF}_{n, j}=\sum_{r} \kappa_{r, n} \times \mathrm{EF}_{j} \times\left(1-\eta_{r, n}\right)$

where: $\mathrm{EF}_{n, j}$ is the $\mathrm{BC}$ emission factor for fuel type $j$ in year $n ; \mathrm{EF}_{j}$ is the uncontrolled BC emission factor for fuel $j, \eta_{r, n}$ is the removal efficiency of device $r$ in year $n$, and $\kappa_{r, n}$ is the use ratio of device $r$ in year $n$.

Table 7 shows the raw emission factors for industry sector, which were obtained from Streets et al. (2001) and Bond et al. (2004), except that $\mathrm{EF}_{\mathrm{BC}}$ for indigenous coking was adjusted to $3.8 \mathrm{~g} \mathrm{~kg}^{-1}$ according to the work by Bond et al. (2007).

\subsection{Power generation and heating}

Power generation and heating sector is the largest coal consumption segment in China, accounting for $49.24 \%$ of national coal use in 2005. However, BC emissions in this sector were low due to high burning temperature and efficient dust control. Like the industry sector, net emission factors of power generation and heating sector change annually due to technology development, which were also calculated by Eq. (6). The applying percentages of various control devices and the removal efficiency of all devices in power generation sector in China in 1995 and 2020 were gained from Streets et al. (2001), as shown in Table 8, which we assumed changed linearly during the estimation period. Raw emission factors in power generation sector were listed in Table 9, obtained from Streets et al. (2001) and Bond et al. (2004).

Burning conditions in heating sector are similar to those in industry sector. Therefore, emission factors for fuels burning in heating sector are the same as EFs in industry sector (Liu and Shao, 2007).

\section{Results and discussion}

\subsection{Temporal evolution of black carbon emissions}

Historical black carbon emissions including five sources were estimated for the period 1980 to 2009, as presented in 
Table 6. Chinese application ratio and removal efficiency for various control devices in industry sector in 1995 and 2020.

\begin{tabular}{l|cc|cc}
\hline Year & \multicolumn{2}{|c|}{1995} & \multicolumn{2}{c}{2020} \\
\hline Control Device & Use ratio & Removal efficiency & Use ratio & Removal efficiency \\
Power-ESP & 0 & 0.98 & 0.1 & 0.98 \\
power-Scrubber & 0.15 & 0.76 & 0.2 & 0.94 \\
Stocker Scrubber & 0.25 & 0.58 & 0.35 & 0.88 \\
Stocker cyclone & 0.55 & 0.9 & 0.35 & 0.95 \\
Stocker none & 0.05 & 0 & 0 & 0 \\
\hline
\end{tabular}

Table 7. Raw emission factors for black carbon in industry sector in China (units: $\mathrm{g} \mathrm{kg}^{-1}$ ).

\begin{tabular}{ll}
\hline Fuel type & Emission factor \\
\hline raw coal & $0.32^{\mathrm{a}}$ \\
briquette coal & $0.003^{\mathrm{a}}$ \\
coke & $0.03136^{\mathrm{b}}$ \\
crude oil & $0.0396^{\mathrm{b}}$ \\
gasoline & $0.006525^{\mathrm{b}}$ \\
kerosene & $0.117^{\mathrm{b}}$ \\
diesel & $0.02646^{\mathrm{b}}$ \\
fuel oil & $0.0396^{\mathrm{b}}$ \\
liquefied petroleum gas & $0.0676^{\mathrm{b}}$ \\
gases & $0.0001^{\mathrm{b}}$ \\
indigenous coking & $0.97^{\mathrm{b}}$ \\
mechanic coking & $3.8^{\mathrm{c}}$ \\
\hline a Streets et al. (2001); ${ }^{\mathrm{b}}$ Bond et al. $(2004) ;$ \\
${ }^{\mathrm{c}}$ Bond et al. (2007)
\end{tabular}

Table 10. Table 10 shows that BC emissions increased by $115.68 \%$ at an annual average rate of $3.99 \%$ from $0.87 \mathrm{Tg}$ in 1980 to $1.88 \mathrm{Tg}$ in 2009. Temporal Chinese BC emissions during the past thirty years were illustrated in Fig. 2. According to Fig. 2, annual black carbon emissions fluctuated during the overall estimation period, with a peak in about 1995 from 1980 to 2000, which was consistent with the results of Streets et al. (2008), who found BC emissions peaked in about 19941995 for the period 1980-2000. Lu et al. (2011) and Ohara et al. (2007) concluded that Chinese BC emissions declined from 1996 to 2000 due to less use of biofuels and coal in the residential and industry sectors, but $\mathrm{BC}$ emissions have begun to increase again since 2000 . This was similar to our finding that $\mathrm{BC}$ emissions had increased at a steady and slow rate of $4.39 \%$ from 1980 to 1995 , then decreased during the late 1990s, and had been continually increasing again from 2000 to 2009, at a faster annual average speed of $6.49 \%$. The changing trends of our emission inventory also matched well with the study by Lei (2008), who found that BC emissions peaked in 1995 from 1990 to 2000, and have then been continually increasing after 2000.

Emissions from five sources increased at considerable different degrees. Residential emissions had grown by $8.66 \%$,

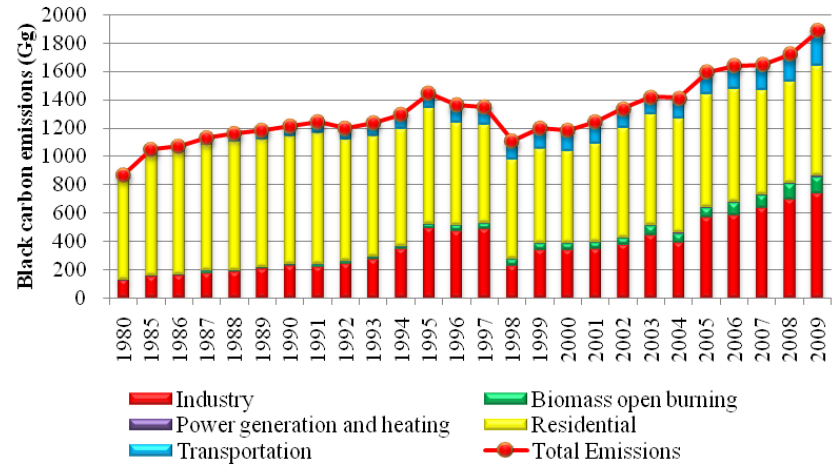

Fig. 2. Historical Black carbon emissions in China from 1980 to 2009.

while emissions from industry, power generation and heating, transportation and biomass open burning had increased by $4.85,7.48,8.44$ and 25.94 times, respectively, from 1980 to 2009. Significant emissions increment in industry sector and power generation and heating sector in spite of the decreased emission factors was due to huge rise of coal consumption in these two sectors, which had enhanced by 4.64 times and 11.90 times, respectively, during the same period. Meanwhile, rapid growth of vehicle population was responsible for the considerable transportation emissions augmentation, which increased from $25.55 \mathrm{Gg}$ in 1980 to $241.19 \mathrm{Gg}$ in 2009. Vehicular emissions showed a slight decrease in the early 21 th century because of the implementation of stricter standards. Nevertheless, due to the rapid increase of vehicle population, the overall changing trend of emissions in this sector was continuously rising, indicating that it might not be possible to put vehicular emissions under control relying solely on executing stricter emission regulations, without controlling total vehicle population.

Annual contributions of the five sources were depicted in Fig. 3, showing that residential contribution declined from $82.03 \%$ in 1980 to $41.33 \%$ in 2009 at a continuous diminishing trend, but had always been the dominant contributor to $\mathrm{BC}$ emissions in China due to poor burning conditions and no control measures taken in this sector. Lu et al. (2011) found residential contributed averagely $51 \% \pm 3 \%$ of total BC emissions from 1996 to 2010, which was similar to our finding that it accounted for $52 \%$ of national $\mathrm{BC}$ emissions 
Table 8. Chinese application ratio and removal efficiency for various control devices in power generation sub-sector in 1995 and 2020.

\begin{tabular}{l|cc|cc}
\hline Year & \multicolumn{2}{|c|}{1995} & \multicolumn{2}{c}{2020} \\
\hline Control Device & Use ratio & Removal efficiency & Use ratio & Removal efficiency \\
Power Filter & 0 & 0.95 & 0.1 & 0.95 \\
power ESP & 0.5 & 0.98 & 0.68 & 0.98 \\
Power Scrubber & 0.35 & 0.76 & 0.2 & 0.94 \\
Power cyclone & 0.1 & 0.95 & 0.02 & 0.95 \\
Stocker Scrubber & 0.02 & 0.76 & 0 & 0.76 \\
Stocker Cyclone & 0.03 & 0.9 & 0 & 0.9 \\
\hline
\end{tabular}

Table 9. Raw emission factors for black carbon in power generation sector in China (units: $\mathrm{g} \mathrm{kg}^{-1}$ ).

\begin{tabular}{ll}
\hline Fuel type & Emission factor \\
\hline raw coal & $0.32^{\mathrm{a}}$ \\
briquette coal & $0.003^{\mathrm{a}}$ \\
crude oil & $0.0396^{\mathrm{b}}$ \\
diesel & $0.02646^{\mathrm{b}}$ \\
fuel oil & $0.0396^{\mathrm{b}}$ \\
Gases & $0.0001^{\mathrm{b}}$ \\
\hline
\end{tabular}

a Streets et al. (2001); ${ }^{\text {b }}$ Bond et al. (2004)

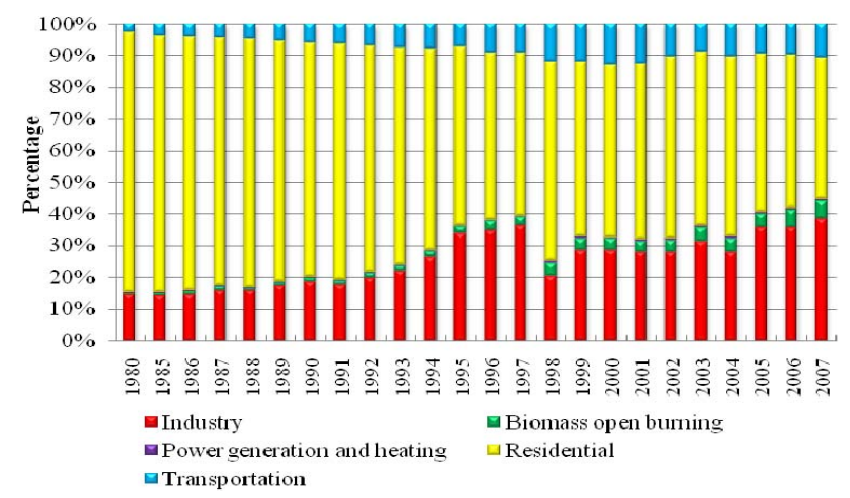

Fig. 3. Contribution of black carbon emissions from five sources in China during the priod 1980-2009.

on average from 1996 to 2009. Contributions of industry sector doubled from $14.39 \%$ in 1980 to $39.05 \%$ in 2009, consistent with the increasing consumption of fossil fuels by both industrial final consumption and coking processes. Power generation and heating sector accounted for about $0.15 \%$ of total BC emissions in 1980, but its contribution had increased by 2.93 times up to 2009 , particularly owing to significant increment of coal consumption by heating sub-sector in the 30 years. Vehicular contributions also increased considerably, from $2.93 \%$ in 1980 to $12.82 \%$ in 2009 , showing a rapid and steady growth rate resulted from substantial vehicle population increase. For example, the population of vans, which were the major contributor to vehicular BC emissions, had boosted by 9.28 times, and the passenger-car population had increased by more than 100 times during this stage.

\subsection{Fuel type and provincial contributions to national BC emissions}

Fossil fuel consumption, biofuel consumption and biomass open burning were included in this emission inventory, and contributions by fuel type were illustrated in Fig. 4. As Fig. 4 shows, fossil fuels were responsible for about $55 \%$ to $65 \%$ of national black carbon emissions, in which $45 \%$ to $55 \%$ were from coal burning and $5 \%$ to $10 \%$ from oil burning. $30 \%$ to $45 \%$ of national black carbon emissions were due to biofuel consumption, with $15 \%$ to $20 \%$ coming from crop residues burning and $15 \%$ to $30 \%$ from firewood burning. Contributions from biomass open burning made up less than $6 \%$ of the overall emissions, mainly resulted from open burning of agricultural wastes. Emissions from natural gas burning, biogas burning, forest fire and grassland fire were negligible, making up less than $1 \%$ of the total emissions. Vehicle contributions increased from $2.93 \%$ in 1980 to $6.02 \%$ in 1990 , and then to $12.82 \%$ in 2009 , resembling the study by Lei (2008) that vehicle contribution increased from $5 \%$ to $11 \%$ during the period 1990-2005. Contributions from fossil fuel combustion had been increasing slowly, with the highest increasing rate in 1995 and 2005. Biofuel contribution decreased from $44.25 \%$ in 1980 to $31.07 \%$ in 2009, despite emissions from this source continued to increase, similar to the finding by Lei (2008) that biofuel accounted for about $35 \%$ of national BC emissions from 1990 to 2005. Therefore, fossil fuels, particularly coal, firewood and crop residues should be taken as control priorities among all energy sources.

Provincial black carbon emissions were also studied to identify the national major contributors and respective main sources in each province. Figure 5 illustrates the provincial emissions of five sectors in 1985, 1995, 2005 and 2009. Provincial contributions had not changed significantly during the estimation period. Generally, the six provinces generating most BC emissions were Shanxi, Sichuan (including Chongqing, Chongqing municipality belonged to Sichuan province before 1997), Hebei, Henan, Hunan and Shandong. They cover merely $14.52 \%$ of China's territory, but were 
Table 10. Black carbon emission inventories in China from 1980 to 2009 (units: Gg).

\begin{tabular}{ccccccc}
\hline Year & Residential & $\begin{array}{c}\text { Biomass open } \\
\text { burning }\end{array}$ & Industry & $\begin{array}{c}\text { Power generation } \\
\text { and heating }\end{array}$ & Transportation & Total \\
\hline 1980 & 715.44 & 4.33 & 125.49 & 1.33 & 25.55 & 872.14 \\
1985 & 848.03 & 7.27 & 148.34 & 2.44 & 42.00 & 1048.07 \\
1986 & 861.11 & 7.84 & 158.02 & 2.61 & 46.09 & 1075.68 \\
1987 & 882.62 & 15.03 & 176.54 & 2.84 & 52.94 & 1129.98 \\
1988 & 909.75 & 9.88 & 182.79 & 3.11 & 58.79 & 1164.33 \\
1989 & 900.92 & 9.84 & 206.29 & 3.34 & 66.81 & 1187.20 \\
1990 & 899.00 & 14.05 & 225.81 & 3.70 & 73.19 & 1215.75 \\
1991 & 922.91 & 15.46 & 218.84 & 4.03 & 79.01 & 1240.25 \\
1992 & 856.80 & 17.16 & 237.57 & 4.34 & 84.51 & 1200.38 \\
1993 & 848.07 & 16.08 & 272.62 & 5.10 & 94.48 & 1236.35 \\
1994 & 825.41 & 20.64 & 342.45 & 5.51 & 104.48 & 1298.50 \\
1995 & 814.20 & 29.25 & 488.93 & 5.66 & 107.85 & 1445.89 \\
1996 & 715.13 & 39.41 & 472.19 & 5.99 & 126.30 & 1359.01 \\
1997 & 693.97 & 38.09 & 485.89 & 5.96 & 126.26 & 1350.17 \\
1998 & 696.34 & 43.16 & 227.39 & 5.70 & 133.74 & 1106.32 \\
1999 & 662.11 & 44.22 & 340.05 & 5.78 & 143.30 & 1195.46 \\
2000 & 647.46 & 43.19 & 337.41 & 6.12 & 153.14 & 1187.32 \\
2001 & 694.10 & 44.52 & 345.18 & 6.65 & 156.16 & 1246.61 \\
2002 & 768.05 & 48.10 & 372.92 & 7.12 & 140.04 & 1336.23 \\
2003 & 779.67 & 61.13 & 443.60 & 7.78 & 125.45 & 1417.64 \\
2004 & 802.70 & 60.45 & 390.48 & 9.27 & 147.30 & 1410.20 \\
2005 & 795.02 & 67.87 & 564.21 & 9.89 & 153.49 & 1590.47 \\
2006 & 793.56 & 87.46 & 584.21 & 9.89 & 162.81 & 1637.92 \\
2007 & 732.68 & 88.70 & 631.46 & 11.33 & 179.89 & 1644.07 \\
2008 & 712.88 & 107.77 & 695.03 & 11.58 & 191.56 & 1718.82 \\
2009 & 777.40 & 116.58 & 734.55 & 11.29 & 241.19 & 1881.01 \\
\hline & & & & & \\
\end{tabular}

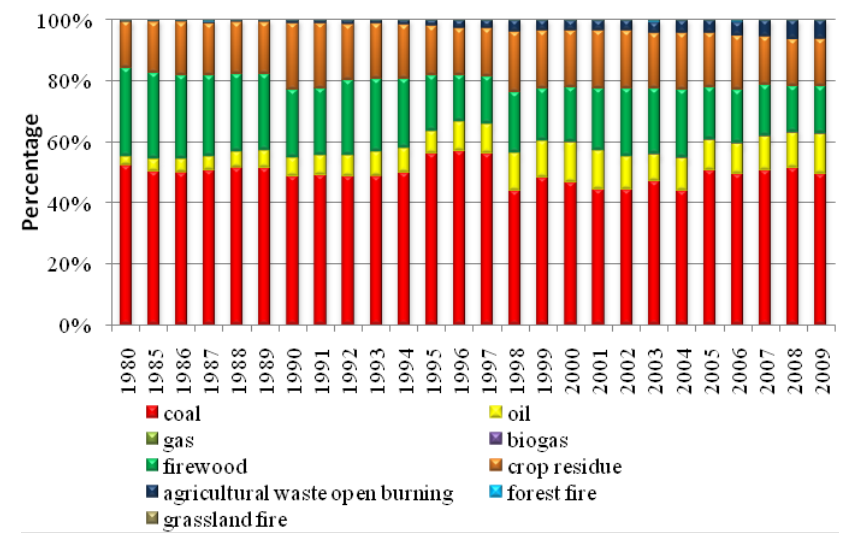

Fig. 4. Contribution of black carbon emissions from various fuel types from 1980-2009.

responsible for $38.61 \%, 43.61 \%, 44.46 \%$ and $45.77 \%$ of the national BC emissions in 1985, 1995, 2005 and 2009, respectively. While the emissions in Xizang, Qinghai, Ningxia, and Hainan districts were all below $10 \mathrm{Gg}$, covering $20.26 \%$ of the national territory, but accounting for $1.31 \%, 0.72 \%$, $1.29 \%$ and $1.49 \%$ of the national BC emissions in 1985 , 1995, 2005 and 2009, correspondingly. Besides, emissions in economically developed areas such as Beijing, Shanghai and Tianjin were usually low.

In the 1980th, when industry was not quite developed and fossil fuel consumption was relatively small, the major emission source in nearly all provinces was the residential sector. After 1990, industry consumption had increased dramatically, making it the second biggest emission contributor in almost all provinces. Particularly, in provinces of Shanxi, Shanghai and Beijing, industry became the dominant contributor. Shanxi province is the largest coke producer in China. Emissions from coking process there were as high as $173.42 \mathrm{Gg}$ and $165.99 \mathrm{Gg}$ in 1995 and 2005, respectively, making up $11.99 \%$ and $10.44 \%$ of the national black carbon emissions, correspondingly, thus resulting in its large industrial emissions.

\subsection{Spatial distribution of the black carbon emissions in China}

Black carbon emission inventories at a high resolution of $0.25^{\circ} \times 0.25^{\circ}$ were established by GIS methodology, as illustrated in Fig. 6, showing the spatial distribution of China's BC emissions in 1985, 1995, 2005 and 2009. 

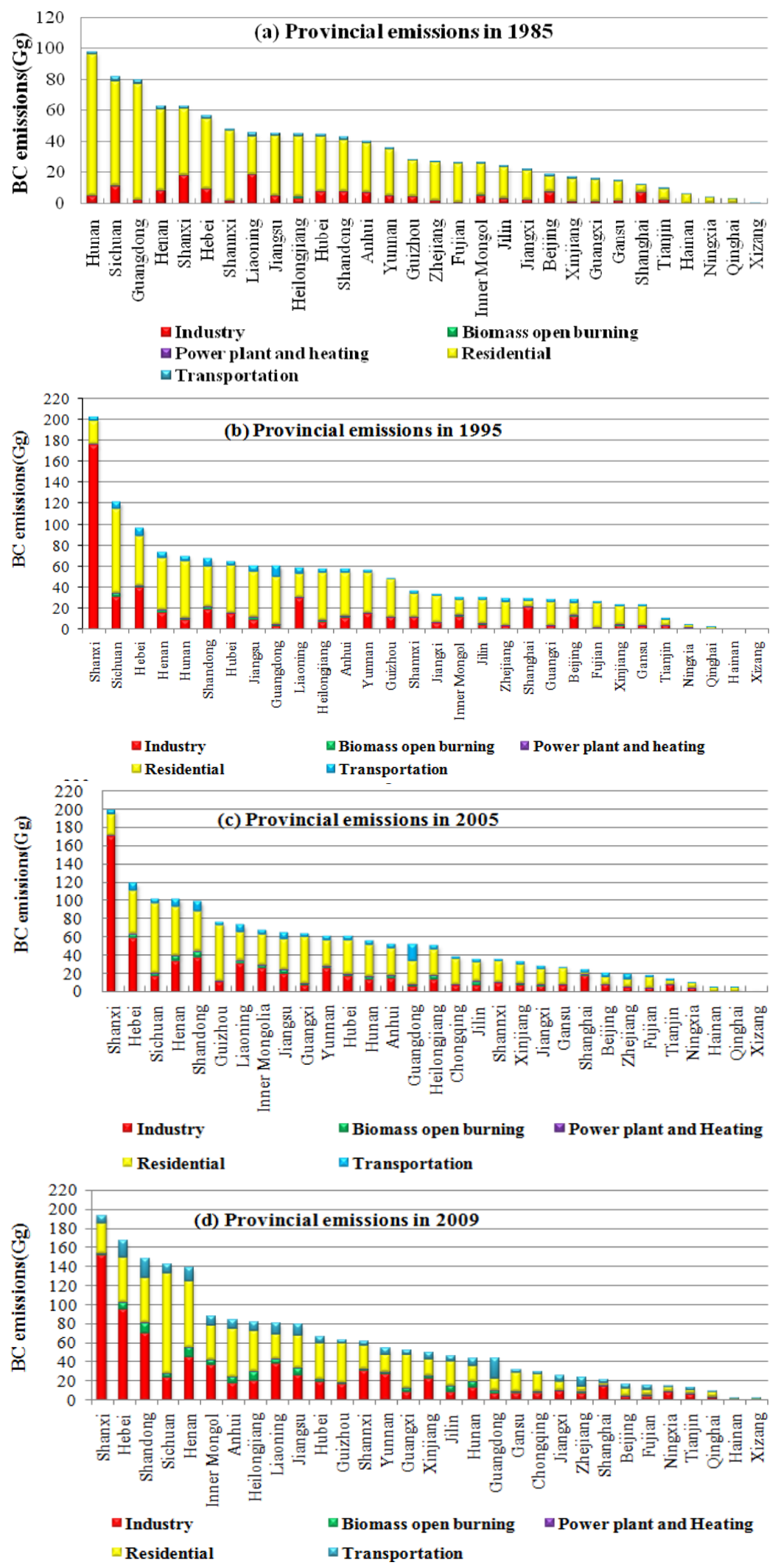

Fig. 5. Anthropogenic black carbon emission inventories for each province in China in (a) 1985, (b) 1995, (c) 2005 and (d) 2009, respectively. 


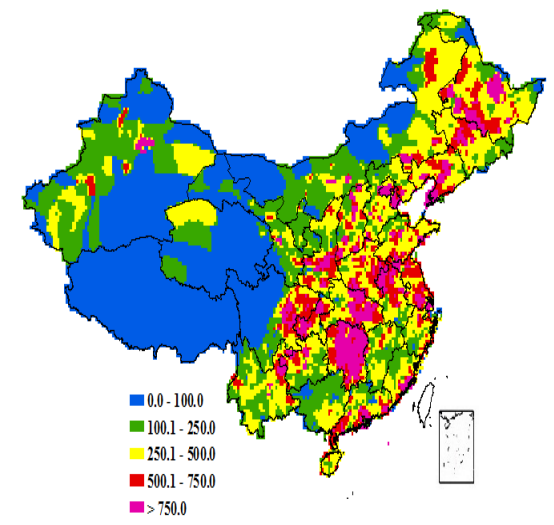

(1985)

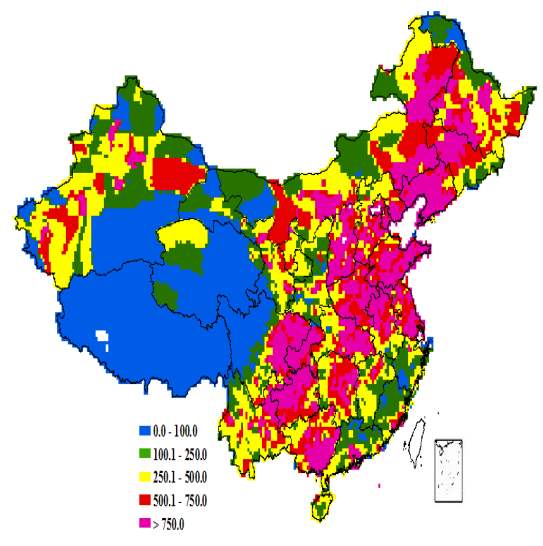

(2005)

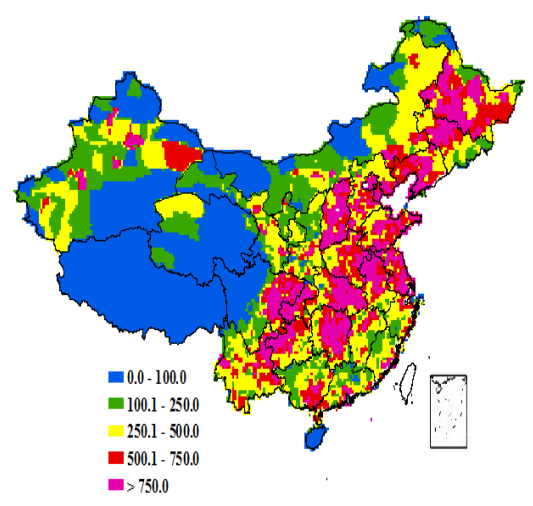

(1995)

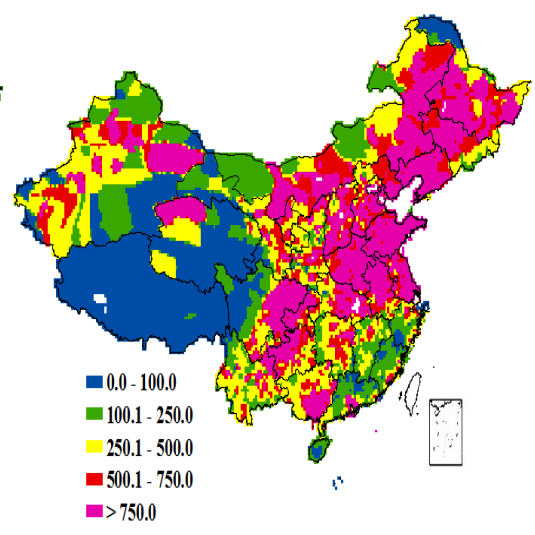

(2009)

Fig. 6. Spatial distribution of black carbon emissions at a resolution of $0.25^{\circ} \times 0.25^{\circ}$ in $1985,1995,2005$ and 2009 (unit: $\mathrm{kg} \mathrm{km}^{-2}$ ).

Figure 6 shows an obvious characteristic of the spatial distribution of China's black carbon emissions that BC emissions were much higher in the central eastern China than in the western China and the southern coastal areas in China. Western China are typically low-emission regions for most pollutants, due to their relatively underdeveloped economy and small consumption of fossil fuels. Western provinces, including Xizang, Xinjiang, Qinghai, Gansu and Ningxia, cover $42.41 \%$ of territory, made up only $3.77 \%, 4.01 \%$, $4.69 \%$ and $5.69 \%$ of national BC emissions in 1985, 1995, 2005 and 2009, respectively. China's Southern coastal regions, and particularly, the Yangtze River Delta and the Pearl River Delta, are generally high-emitting areas for various pollutants because of their large consumption of fossil fuels. However, the overall $\mathrm{BC}$ emissions in these regions were not high due to low residential $\mathrm{BC}$ emissions. The central eastern districts, three northeastern provinces and the Sichuan Basin stood out with the highest emissions owing to their significant emissions from residential and industry sectors, covering $22.30 \%$ of China's territory, but were responsible for $43.02 \%, 50.47 \%, 50.69 \%$ and $54.30 \%$ of the national BC emissions in 1985, 1995, 2005 and 2009, respectively.

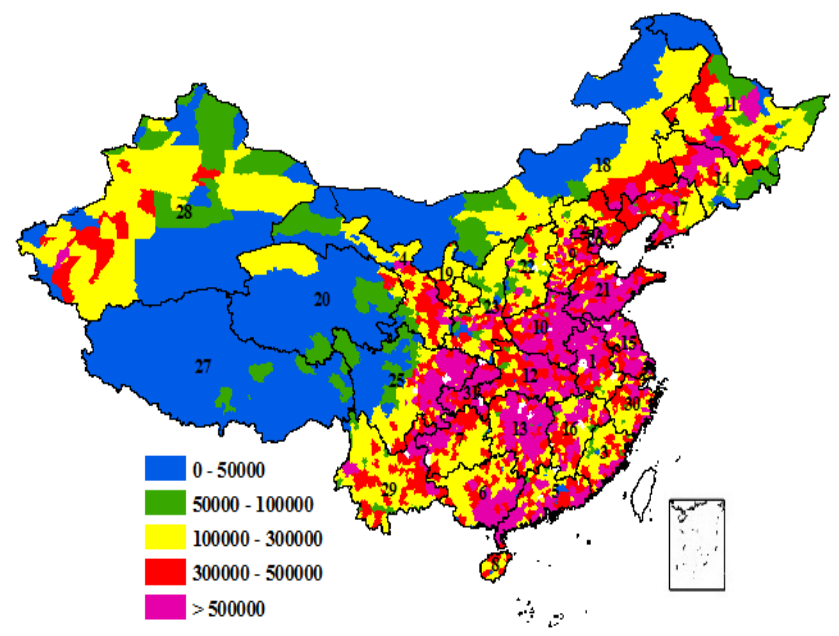

Fig. 7. Spatial distribution of rural population at county level in 2000 (unit: per person/per county). 
A map with the names of China's 31 provinces was provided in Fig. 7, which also shows the spatial distribution of Chinese rural population in 2000. Compared Figs. 6 with 7, the spatial distribution of national $\mathrm{BC}$ emissions was obviously similar to the distribution of the rural population, suggesting that residential was the major contributor to $\mathrm{BC}$ emissions in China.

Black carbon emissions were mainly distributed along a line from Heilongjiang to Sichuan province, and these high emission regions had begun to scatter around the line, resulting in the expansion of high emission regions from 1985 to 2009. Figure 6 also shows that the spatial distribution of BC emissions in 1985, 1995, 2005 and 2009 was similar, but the emission levels in those high-emitting areas had been rising and high emission regions had been expanding over the years.

To discern the characteristics of the temporal and spatial distribution of emission from different sources, the spatial distribution of emissions from the five sectors was illustrated at a high resolution of $0.25^{\circ} \times 0.25^{\circ}$ for $1985,1995,2005$ and 2009, respectively, as shown in Fig. 8. In the spatial distribution of $\mathrm{BC}$ emissions from transportation shown in Fig. 8a, emissions from vehicles and aviation were obviously higher in southeastern coastal areas than in western and northeastern China. The Yangtze River Delta, Pearl River Delta, and Bohai Rim, particularly the districts of Guangdong, Beijing, Shanghai, and Tianjin, were the dominant emission contributors in this sector, covering $1.99 \%$ of China's territory while generating $14.62 \%, 17.43 \%, 19.41 \%$ and $13.82 \%$ of total BC emissions from transportation in 1985, 1995, 2005 and 2009 , respectively. Furthermore, high emissions were mainly concentrated in cities, especially capital cities, which cover $0.8 \%$ of China's territory, but resulted in $21.72 \%$ of total emissions in this sector in 2005. Temporally, emission intensity from transportation had increased significantly from 1985 to 2009 , mainly resulting from the rapid increase of vehicle population.

Figure 8b, illustrating the spatial distribution of $\mathrm{BC}$ emissions from biomass open burning, shows that emissions from biomass open burning were concentrated in the northeastern provinces of Jilin, Liaoning and Heilongjiang, central provinces of Shandong, Henan, Anhui and Jiangsu, and southern provinces of Guangdong, Guangxi, and Hunan, due to large crop residues production and relatively high burning ratios in these districts. Temporally, high emission regions in this sector had expanded from central provinces to northeastern and southern provinces from 1985 to 2009.

The spatial distribution of $\mathrm{BC}$ emissions from residential was illustrated in Fig. 8c, which was closest to the distribution of national $\mathrm{BC}$ emission. The temporal evolution shows that the spatial distribution of residential emissions had almost remained the same from 1985 to 2009, with provinces of Sichuan, Guizhou, Hubei, Hunan, Jiangsu, Anhui, Shandong, Jilin, Liaoning and Heilongjiang and Chongqing municipality being the dominant contributor. The above districts cover $24.54 \%$ of China's territory, but resulted in $47.24 \%$, $52.00 \%, 52.40 \%$ and $56.09 \%$ of total residential emissions in 1985, 1995, 2005 and 2009, respectively.

The spatial distribution of $\mathrm{BC}$ emissions from industry was illustrated in Fig. 8d, which shows that BC emissions in the industrial sector were especially high in Shanxi, Shandong and Hebei provinces and in Beijing and Shanghai municipalities. These districts cover $5.54 \%$ of China's territory but generated $33.69 \%, 55.24 \%, 50.85 \%$ and $45.43 \%$ of total emissions from industry sector, with Shanxi province alone contributing $12.25 \%, 35.85 \%, 29.82 \%$ and $20.54 \%$ in 1985 , 1995, 2005 and 2009, respectively. Due to twenty years' industrialization, the areas with high industrial BC emissions had expanded significantly among the central and eastern provinces.

Figure 8e shows the spatial distribution of $\mathrm{BC}$ emissions from the power generation and heating sector. $\mathrm{BC}$ emissions from this sector were mainly concentrated in the northeastern provinces of Heilongjiang, Jilin, and Liaoning, where much heating is required. Temporally, high BC emissions from this sector had been expanding from three northeastern provinces to the middle-eastern China, i.e. Shandong and Jiangsu provinces, from 1980 to 2009. These five provinces, covering $12.11 \%$ of China's territory, were responsible for $37.57 \%, 43.71 \%, 42.15 \%$ and $43.55 \%$ of the total BC emissions from this sector in 1985, 1995, 2005 and 2009, respectively.

\subsection{Comparison of black carbon emission inventories and uncertainty analysis}

Many scholars have tried to develop Chinese BC emission inventories covering certain years or certain sources. For example, Ohara et al. (2007) established an Asian emission inventory based on fuel consumption data, and estimated all anthropogenic BC emissions in China for the period 19802000, excluding open biomass burning. Junker and Liousse (2008) constructed a global carbonaceous aerosol emission inventory from 1860 to 1997 , also omitting biomass open burning. Lu et al. (2011) provided Chinese BC emissions from 1996 to 2010 with activity rates extrapolated from 2008 to 2010 based on national fast-track statistics. Our study was the first time to build Chinese historical BC emission inventories using a consistent methodology, including fossil fuel and biofuel consumption, as well as biomass open burning, covering a range of $30 \mathrm{yr}$. Results of our studies were compared with other studies, as presented in Fig. 9.

Figure 9 shows that the result of Ohara et al. (2007) was slightly higher than our estimation before 1995, but was lower thereafter, with the relative error less than $20 \%$ between these two studies during the overall period. Fuel consumption data employed by Ohara et al. (2007) from 1980 to 1995 were from IEA Energy Balances, and were from China Energy Statistical Yearbooks for the period 1996-2003. Activity data source also changed in 1995, suggesting that the 


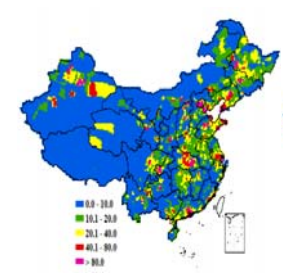

(1985)

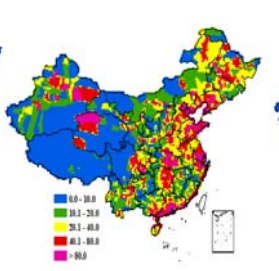

(1995)

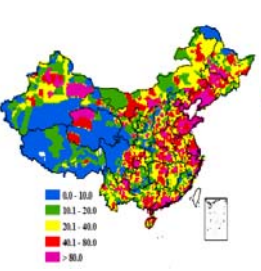

(2005)

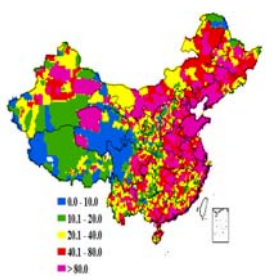

(2009)

(a)

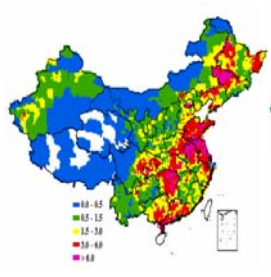

(1985)

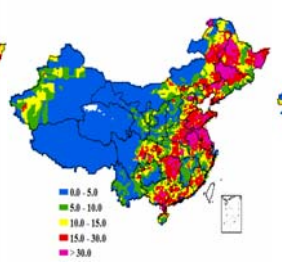

(1995)

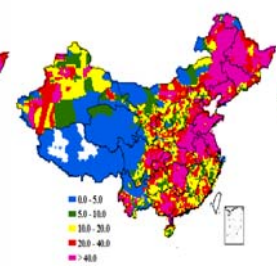

(2005)

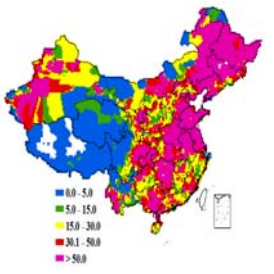

(2009)

(b)

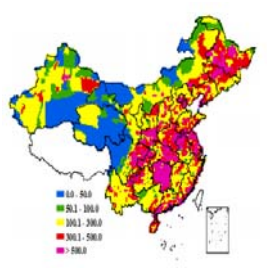

(1985)

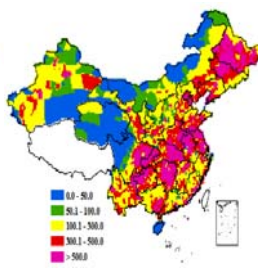

(1995)

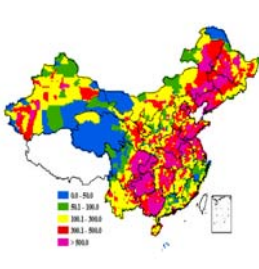

(2005)

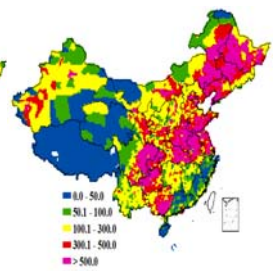

(2009)

(c)

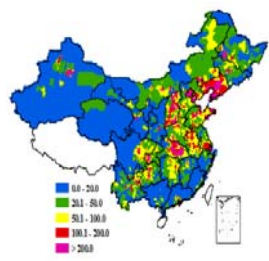

(1985)

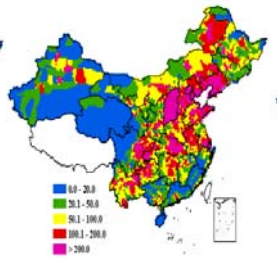

(1995)

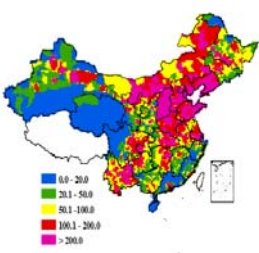

(2005)

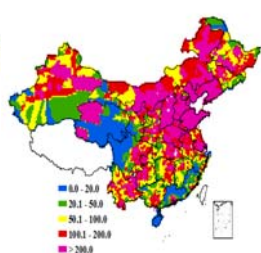

(2009)

(d)

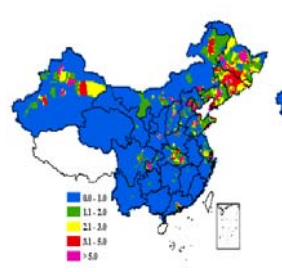

(1985)

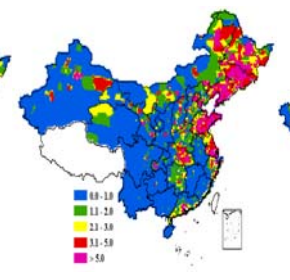

(1995)

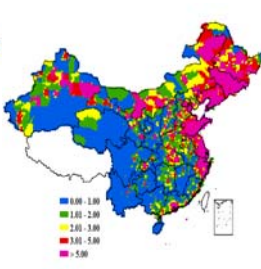

(2005)

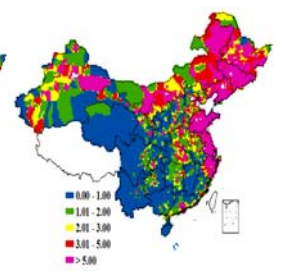

(2009)

(e)

Fig. 8. Spatial distribution of black carbon emissions at a resolution of $0.25^{\circ} \times 0.25^{\circ}$ for (a) transportation source, (b) biomass open burning, (c) residences, (d) industry, and (e) power generation and heating in 1985, 1995, 2005 and 2009, based on GIS methodology (unit: kg km ${ }^{-2}$ ). 


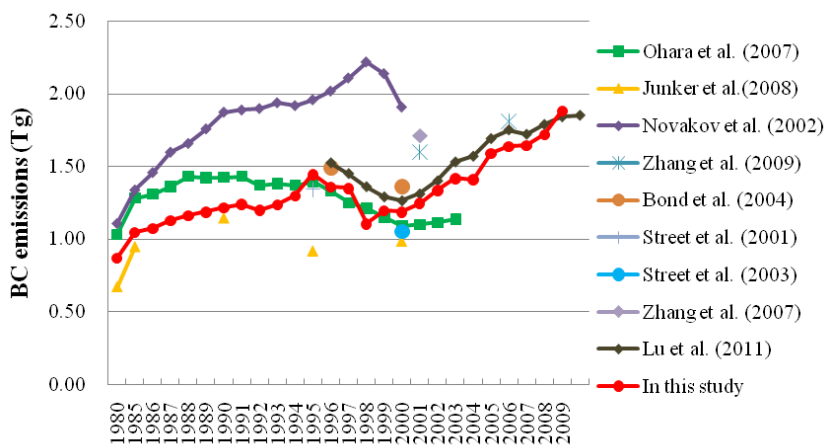

Fig. 9. Comparison of China's historical black carbon emission inventories.

activity data may have resulted in the discrepancy between these two studies. Comparing their BC emissions from each source in 2000 with ours, it was found that their industrial emissions, omitting emissions from industrial process, were merely $99 \mathrm{Gg}$ (about $200 \mathrm{Gg}$ lower than ours). Junker and Liousse (2008)'s estimation, leaving out emissions from biomass open burning, had always been lower than our results from 1980 to 2000. While the results of Novakov et al. (2003) were obviously higher than ours, though it only included fossil fuel emissions. Emission factors used by Novakov et al. (2003) were from Cooke et al. (1999), which were thought to be unrepresentative (Streets et al., 2004), and which were responsible for larger estimated emissions compared with most other results (Ito and Penner, 2005; Junker and Liousse, 2008; Ohara et al., 2007). Nevertheless, it showed a similar increasing trend of $\mathrm{BC}$ emissions during 1980-1995 to our estimation. Compared with Lu et al. (2011), the overall changing trend of both studies were similar, especially that $\mathrm{BC}$ emissions decreased in the late 1990s while showed a constant increasing trend in the 21 century. In our study, total BC emissions reduced in 1998 because of significant decreased coking $\mathrm{BC}$ emissions as the ratio of mechanic coking to indigenous coking was relatively high in that year. This was because China officially banned indigenous coking in 1996, coking production reached the high value in 1997 and then quickly dropped. However, indigenous coking recovered in the 21 st century due to the market demand. Lu et al. (2011)'s results were generally larger compared with our estimation mainly because of residential emissions. In Lu et al. (2011)'s study, they estimated BC emissions by biofuel consumption increased by $48.33 \%$ from $418 \mathrm{Gg}$ in 1996 to $620 \mathrm{Gg}$ in 2008, while in our study, this increase is about $27.07 \%$. During this period, total biofuel consumption increased by $27.58 \%$ (NBS). Simultaneously, Lu et al. (2011) estimated the net EFs increased by merely $0.12 \%$. Therefore, it is questionable their estimated $\mathrm{BC}$ emissions by biofuel burning experienced such great increment. Emissions from both industry and power generating and heating sectors were larger in Lu et al. (2011)'s study compared with our results in general. Considering that both study obtained the activity rates from the official public data, differences in these two sectors were likely to be resulted from the larger EFs applied in Lu et al. (2011)'s study. Estimated BC emissions from biomass open burning by $\mathrm{Lu}$ et al. (2011) were also larger than ours. EFs for residues' open burning in our study were from local experiments (Cao et al., 2007), while Lu et al. (2011) used updated EFs by Professor Tami Bond on the basis of their previous work (Bond et al., 2004). Besides, in our study, residues' region-specific open burning ratios during the estimation period were based on the local survey (Wang and Zhang, 2008), and the per capita average peasant income (Qin and Xie, 2011b). Therefore, both EFs and open burning ratios applied resulted in the difference. Transportation emissions in their study were lower than ours before 2000, while much larger after 2004. In our study, vehicular emissions were calculated based on the mileage and population of different vehicle types, as well as vehicular-specific EFs from the COPERT model. While Lu et al. (2011) calculated vehicular BC emissions according to oil consumption data. Because only fuel used in commercial activities are recorded in the statistics, and oil consumption by transportation, warehousing, and postal service are recorded together. The discrepancy of transportation emissions was resulted from both the estimation method and the data difference.

Streets et al. (2001, 2003a) and Bond et al. (2004) estimated BC emissions based on RAINS-Asia model or predicted energy consumption by Sinton and Fridley (2000), thus their inventories were highly uncertain. Emissions estimation after 2000 by Zhang et al. (2009), Zhang et al. (2007) were generally larger than our estimation, because of higher emission factors used, despite the fact that they did not take biomass open burning into account. The estimation of emissions in 2006 by Zhang et al. (2009) were based on a mixture of trend extrapolations from 2004/2005 and actual 2006 data due to data deficiency, thus it cannot accurately quantify Chinese BC emissions in 2006. Besides, domestic emission factors for residential sector (Chen et al., 2009; Li et al., 2009; Shen et al., 2010) and biomass open burning (Cao et al., 2007), which accounted for $61.14 \%$ and $88.83 \%$ of national BC emissions in Cao et al. (2006) and Streets et al. (2001), respectively, were introduced in our work. Therefore, our work has made significant improvement in comparison with the result of Zhang et al. (2009). According to our estimation, BC emissions have not increased that drastically after 2000 as previously predicted (Ramanathan and Carmichael, 2008), but were at a much more steady and gradual growth rate because of advanced dust control technology applied and severer emission regulations executed. Besides, compared with the top-down estimation of Fu et al. (2012), their estimation of $\mathrm{BC}$ emissions was $62.23 \%$ higher than our estimation in 2009. This was similar to their finding that their results were at least $60 \%$ higher than all previous bottom-up estimates. 


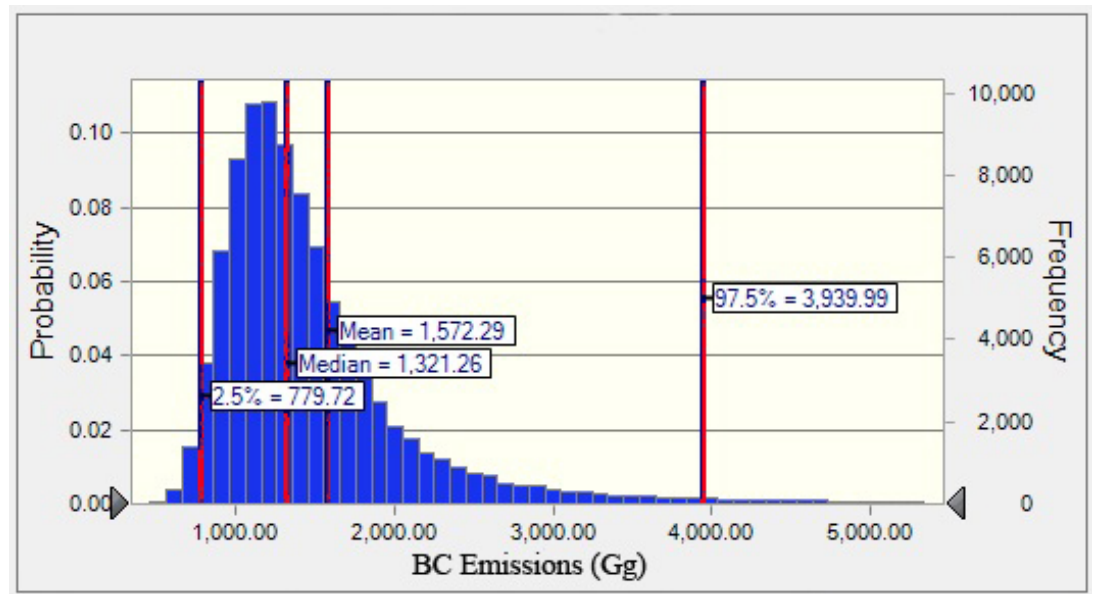

(2005)

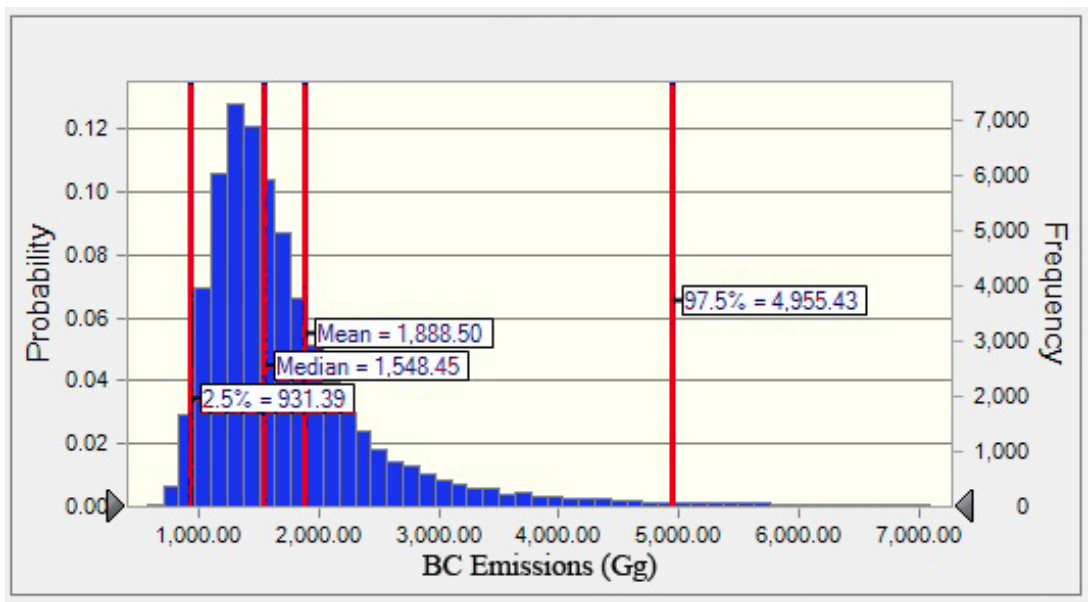

(2009)

Fig. 10. Uncertainty analysis for Chinese black carbon emission inventories in 2005 and 2009 based on 100000 Monte Carlo simulations.

More regional measurements with better spatiotemporal coverage are needed for better understanding of this gap.

Black carbon emissions were hard to quantify accurately as they depend on the combustion process (Streets et al., 2001). Thus Monte Carlo simulation was conducted to quantify the uncertainty of the emission inventory resulted from emission factors and activity data. The lognormal distribution was assumed for all emission factors in each subsector (Bond et al., 2004), and the assumption by Zhao et al. (2011) was generally applied concerning activity data. Refer to Qin and Xie (2011a) for the detailed method.

After determining the probability density function (PDF) of EFs and activity data for each sector, Monte Carlo simulation with randomly selected values within the respective PDFs was repeatedly implemented for 100000 times. The uncertainty in Chinese BC emission inventory in 2005 and 2009 at the $95 \%$ confidence interval were obtained, as shown in Fig. 10. The mean value, 2.5th percentile value, and 97.5th percentile value were $1572.29,779.72$ and $3939.99 \mathrm{Gg}$ (2005) and $1888.50,931.39$, and $4955.43 \mathrm{Gg}$ (2009), respectively. Therefore, the propagation of uncertainty of this emission inventory at the $95 \%$ confidence interval in 2005 and 2009 were about $[-50.98 \%, 147.72 \%]$ and $[-50.49 \%, 163.45 \%]$, correspondingly. Results showed that the emission inventory uncertainty was most sensitive to the emission factors of mechanic coking, indigenous coking, residues, firewood and bituminous briquette.

To understand Chinese contributions to total BC emissions in East Asia, Asia, and the whole world, we used our results and references dealing with $\mathrm{BC}$ emissions on other scales for discussion. For instance, Ohara et al. (2007) estimated BC emissions in East Asia (1980-2003) without considering biomass open burning. Streets et al. (2008) presented total BC emissions in Asia from 1980 to 2000. Both Bond et al. (2007) and Bond et al. (2004) estimated global BC emissions in certain years, but the former did not include 


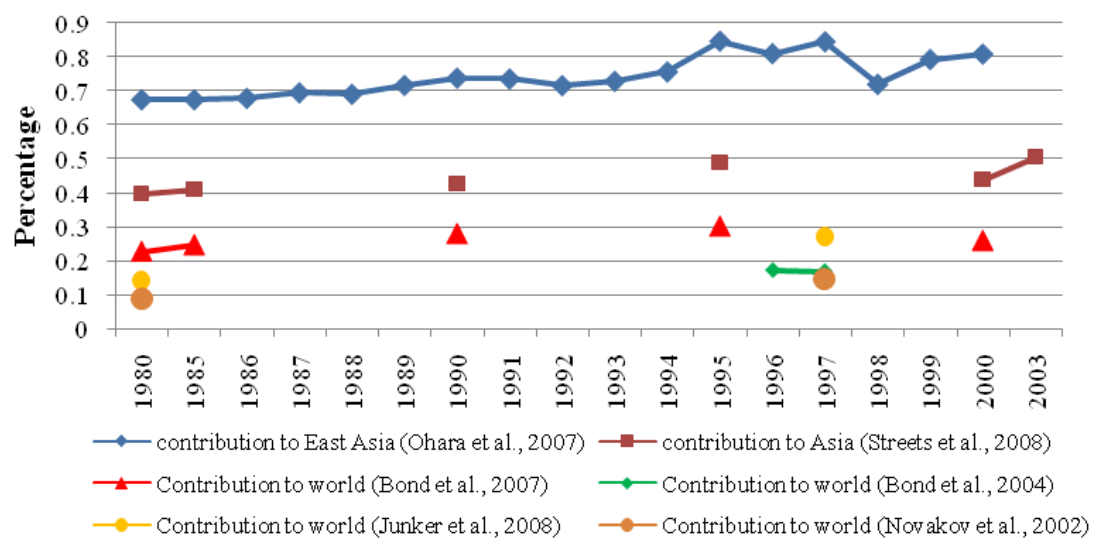

Fig. 11. Contributions of China's black carbon emission to East Asia, Asia and the whole world.

emissions from biomass open burning. Because some emission inventories were not complete, Chinese contributions to $\mathrm{BC}$ emissions in East Asia, Asia and the whole world were illustrated in Fig. 11 based on corresponding source emissions. For example, the contributions of China to East Asia were represented by the ratio of Chinese emissions excluding biomass burning to the East Asia emissions in corresponding years, regarding that biomass burning emissions were omitted in the East Asia emission inventories.

As shown by Fig. 11, in general, contributions from China had been increasing from 1980 to the middle 1990s, which decreased in the late 1990s and began to rise again in 2000. Figure 11 shows that Chinese $\mathrm{BC}$ emissions were responsible for about $70 \%-85 \%$ of emissions in East Asia, which increased from $67 \%$ in the 1980 s to $85 \%$ in the middle 1990s, and then decreased to about $80 \%$ in the late 1990 s. As to Asia, Chinese contributions increased from $39.75 \%$ in 1980 to $50.59 \%$ in 2003, making up about half of the emissions in Asia; and the contribution was $43.99 \%$ in 2000, slightly higher than the estimation of $41 \%$ by Streets et al. (2003a). Concerning Chinese contribution to the global $\mathrm{BC}$ emissions, it showed a similar changing trend to contributions at other scales. Based on global emissions calculated by Bond et al. (2007), China accounted for $26.35 \%$ of the global BC emissions on average. However, the contributions were much lower based on the results by Junker and Liousse (2008), Novakov et al. (2003) and Bond et al. (2004). For instance, the contributions were merely $8.76 \%$ in 1980 and $14.83 \%$ in 1997 when estimated global emissions by Novakov et al. (2003) were used. Nevertheless, Chinese contributions to the global emissions had been increasing obviously, and China was responsible for averagely $18.97 \%$ of the global $\mathrm{BC}$ emissions during the estimation period.

\section{Conclusions}

For the first time, Chinese multi-year black carbon emission inventories including fossil fuel consumption, biofuel consumption and biomass open burning were constructed for the period 1980-2009. Official statistical data at county and provincial level were used, and temporal emission factor changes due to technology development and the introduction of stricter vehicular emission regulations were taken into account. The emission inventories were further allocated to the county level and illustrated at a high resolution of $0.25^{\circ} \times 0.25^{\circ}$ by GIS methodology.

National BC emissions had increased by $115.68 \%$ at an annual average rate of $3.99 \%$ from $0.87 \mathrm{Tg}$ in 1980 to $1.88 \mathrm{Tg}$ in 2009 . During the overall estimation period, annual black carbon emissions fluctuated with one peak in about 1995, and had been continuously increasing in the first decade of the 21 century. Obvious discrepancies were found among five sources regarding their contributions to total BC emissions from 1980 to 2009. Residential contribution declined from $82.03 \%$ in 1980 to $41.33 \%$ in 2009 at a continuous diminishing trend, but had always been the dominant contributor due to poor burning conditions and no controls taken in this sector. Contribution of industry sector doubled from $14.39 \%$ in 1980 to $39.05 \%$ in 2009 , and contribution of power generation and heating sector had increased by 2.93 times during the same time. Vehicular contributions also showed considerable increase, from $2.93 \%$ in 1980 to $12.82 \%$ in 2009 owing to substantial vehicle population increase, despite the introduction of severer emission standards, suggesting that it might not be possible to put vehicular emissions under control relying solely on implementing stricter emission regulations. Fossil fuels were responsible for about $55 \%$ to $65 \%$ of national BC emissions, in which $45 \%$ to $55 \%$ came from coal burning; whereas biofuels accounted for $30 \%$ to $45 \%$ of national black carbon emissions. 
The spatial distribution of China's black carbon emissions revealed that $\mathrm{BC}$ emissions were mainly concentrated in the central eastern districts, the three northeastern provinces and the Sichuan Basin. These districts cover 22.30\% of China's territory, but were responsible for $43.02 \%, 50.47 \%, 50.69 \%$ and $54.30 \%$ of the national BC emissions in 1985,1995 , 2005 and 2009, respectively. Besides, emission levels in those high-emitting areas had been rising and high emission regions had been expanding over the years. In general, China was responsible for $70 \%-85 \%$ of emissions in East Asia, or half of the emissions in Asia. China's contribution to global black carbon emissions was more controversial, but it is clear that contributions from China had been increasing from 1980 to 2003 , and China accounted for averagely $18.97 \%$ of the global BC emissions.

\section{Supplementary material related to this article is available online at: http://www.atmos-chem-phys.net/12/ 4825/2012/acp-12-4825-2012-supplement.zip.}

Acknowledgements. This research was supported by a grant from the Major State Basic Research Development Program of China (973 Program) (No. 2010CB955608) and Environmental Public Service Research Fund (No. 2011467003).

Edited by: T. Wang

\section{References}

Andreae, M. O. and Merlet, P.: Emission of trace gases and aerosols from biomass burning, Global Biogeochem. Cy., 15, 955-966, 2001.

Aunan, K., Fang, J. H., Hu, T., Seip, H. M., and Vennemo, H.: Climate change and air quality - Measures with co-benefits in China, Environ. Sci. Technol., 40, 4822-4829, 2006.

Bo, Y., Cai, H., and Xie, S. D.: Spatial and temporal variation of historical anthropogenic NMVOCs emission inventories in China, Atmos. Chem. Phys., 8, 7297-7316, doi:10.5194/acp-8-72972008, 2008.

Bond, T. C., Streets, D. G., Yarber, K. F., Nelson, S. M., Woo, J. H., and Klimont, Z.: A technology-based global inventory of black and organic carbon emissions from combustion, J. Geophys. Res.-Atmos., 109, D14203, doi:10.1029/2003JD003697, 2004.

Bond, T. C., Bhardwaj, E., Dong, R., Jogani, R., Jung, S. K., Roden, C., Streets, D. G., and Trautmann, N. M.: Historical emissions of black and organic carbon aerosol from energy-related combustion, 1850-2000, Global Biogeochem. Cy., 21, GB2018, doi:10.1029/2006GB002840, 2007.

Cai, H. and Xie, S. D.: Estimation of vehicular emission inventories in China from 1980 to 2005, Atmos. Environ., 41, 8963-8979, 2007.
Cao, G. L., Zhang, X. Y., and Zheng, F. C.: Inventory of black carbon and organic carbon emissions from China, Atmos. Environ., 40, 6516-6527, doi:10.1016/j.atmosenv.2006.05.070, 2006.

Cao, G. L., Zhang, X. Y., Wang, Y. Q., and Zheng, F. C.: Estimation of China's regional agricultural waste open burning emissions, Chin. Sci. Bull., 52, 1826-1831, 2007.

Chen, Y. J., Sheng, G. Y., Bi, X. H., Feng, Y. L., Mai, B. X., and $\mathrm{Fu}$, J. M.: Emission factors for carbonaceous particles and polycyclic aromatic hydrocarbons from residential coal combustion in China, Environ. Sci. Technol., 39, 1861-1867, 2005.

Chen, Y. J., Zhi, G. R., Feng, Y. L., Fu, J. M., Feng, J. L., Sheng, G. Y., and Simoneit, B. R. T.: Measurements of emission factors for primary carbonaceous particles from residential rawcoal combustion in China, Geophys. Res. Lett., 33, L20815, doi:10.1029/2006GL026966, 2006.

Chen, Y. J., Zhi, G. R., Feng, Y. L., Liu, D. Y., Zhang, G., Li, J., Sheng, G. Y., and Fu, J. M.: Measurements of Black and Organic Carbon Emission Factors for Household Coal Combustion in China: Implication for Emission Reduction, Environ. Sci. Technol., 43, 9495-9500, 2009.

China Automobile Industry Association: China Automobile Industry Yearbooks [M], China Machine Press, Beijing, China, 19852010.

Cooke, W. F., Liousse, C., Cachier, H., and Feichter, J.: Construction of a 1 degrees $\times 1$ degrees fossil fuel emission data set for carbonaceous aerosol and implementation and radiative impact in the ECHAM4 model, J. Geophys. Res.-Atmos., 104, 22137$22162,1999$.

de Zarate, I. O., Ezcurra, A., Lacaux, J. P., Van Dinh, P., and de Argandona, J. D.: Pollution by cereal waste burning in Spain, Atmos. Res., 73, 161-170, 2005.

Fu, T.-M., Cao, J. J., Zhang, X. Y., Lee, S. C., Zhang, Q., Han, Y. M., Qu, W. J., Han, Z., Zhang, R., Wang, Y. X., Chen, D., and Henze, D. K.: Carbonaceous aerosols in China: top-down constraints on primary sources and estimation of secondary contribution, Atmos. Chem. Phys., 12, 2725-2746, doi:10.5194/acp12-2725-2012, 2012.

IPCC (Intergovernmental Panel on Climate Change): Greenhouse Gas Inventory Reference Manual, IPCC/OECD/IES, UK Meteorological Office, Bracknell, UK, 2006.

Ito, A. and Penner, J. E.: Historical emissions of carbonaceous aerosols from biomass and fossil fuel burning for the period 1870-2000, Global Biogeochem. Cy., 19, GB2028, doi:10.1029/2004GB002374, 2005.

Junker, C. and Liousse, C.: A global emission inventory of carbonaceous aerosol from historic records of fossil fuel and biofuel consumption for the period 1860-1997, Atmos. Chem. Phys., 8, 1195-1207, doi:10.5194/acp-8-1195-2008, 2008.

Kopp, R. E. and Mauzerall, D. L.: Assessing the climatic benefits of black carbon mitigation, P. Natl. Acad. Sci. USA, 107, 1170311708, 2010.

Lal, R.: World crop residues production and implications of its use as a biofuel, Environ. Int., 31, 575-584, 2005.

Lavoue, D., Liousse, C., Cachier, H., Stocks, B. J., and Goldammer, J. G.: Modeling of carbonaceous particles emitted by boreal and temperate wildfires at northern latitudes, J. Geophys. Res.Atmos., 105, 26871-26890, 2000.

Li, X. H., Wang, S. X., Duan, L., Hao, J. M., and Nie, Y. F.: Carbonaceous Aerosol Emissions from Household Biofuel Combus- 
tion in China, Environ. Sci. Technol., 43, 6076-6081, 2009.

Liu, Y. and Shao, M.: Estimation and prediction of black carbon emissions in Beijing City, Chin. Sci. Bull., 52, 1274-1281, 2007.

Lu, Z., Zhang, Q., and Streets, D. G.: Sulfur dioxide and primary carbonaceous aerosol emissions in China and India, 1996-2010, Atmos. Chem. Phys., 11, 9839-9864, doi:10.5194/acp-11-98392011, 2011.

Menon, S., Hansen, J., Nazarenko, L., and Luo, Y. F.: Climate effects of black carbon aerosols in China and India, Science, 297, 2250-2253, 2002.

National Bureau of Statistics: China Energy Statistical Yearbooks, China Statistics Press, Beijing, 1986-2010.

Novakov, T., Ramanathan, V., Hansen, J. E., Kirchstetter, T. W., Sato, M., Sinton, J. E., and Sathaye, J. A.: Large historical changes of fossil-fuel black carbon aerosols, Geophys. Res. Lett., 30, 1324, doi:10.1029/2002GL016345, 2003.

Ohara, T., Akimoto, H., Kurokawa, J., Horii, N., Yamaji, K., Yan, $\mathrm{X}$., and Hayasaka, T.: An Asian emission inventory of anthropogenic emission sources for the period 1980-2020, Atmos. Chem. Phys., 7, 4419-4444, doi:10.5194/acp-7-4419-2007, 2007.

Qin, Y. and Xie, S. D.: Estimation of county-level black carbon emissions and its spatial distribution in China in 2000, Atmos. Environ., 45, 6995-7004, 2011a.

Qin, Y. and Xie, S. D.: Historical estimation of carbonaceous aerosol emissions from biomass open burning in China for the period 1990-2005, Environ Pollut, 159, 3316-3323, 2011 b.

Ramanathan, V. and Carmichael, G.: Global and regional climate changes due to black carbon, Nat. Geosci., 1, 221-227, 2008.

Reddy, M. S. and Venkataraman, C.: Atmospheric optical and radiative effects of anthropogenic aerosol constituents from India, Atmos. Environ., 34, 4511-4523, 2000.

Reddy, M. S. and Venkataraman, C.: Inventory of aerosol and sulphur dioxide emissions from India. Part II - biomass combustion, Atmos. Environ., 36, 699-712, 2002.

Rypdal, K., Rive, N., Berntsen, T. K., Klimont, Z., Mideksa, T. K., Myhre, G., and Skeie, R. B.: Costs and global impacts of black carbon abatement strategies, Tellus B, 61, 625-641, 2009.

Saikawa, E., Naik, V., Horowitz, L. W., Liu, J. F., and Mauzerall, D. L.: Present and potential future contributions of sulfate, black and organic carbon aerosols from China to global air quality, premature mortality and, radiative forcing, Atmos. Environ., 43, 2814 $2822,2009$.

Sato, M., Hansen, J., Koch, D., Lacis, A., Ruedy, R., Dubovik, O., Holben, B., Chin, M., and Novakov, T.: Global atmospheric black carbon inferred from AERONET, P. Natl. Acad. Sci. USA, 100, 6319-6324, 2003.

Shen, G. F., Yang, Y. F., Wang, W., Tao, S., Zhu, C., Min, Y. J., Xue, M. A., Ding, J. N., Wang, B., Wang, R., Shen, H. Z., Li, W., Wang, X. L., and Russell, A. G.: Emission Factors of Particulate Matter and Elemental Carbon for Crop Residues and Coals Burned in Typical Household Stoves in China, Environ. Sci. Technol., 44, 7157-7162, 2010.

Sinton, J. E. and Fridley, D. G.: What goes up: recent trends in China's energy consumption, Energ. Policy, 28, 671-687, 2000.

Streets, D. G., Gupta, S., Waldhoff, S. T., Wang, M. Q., Bond, T. C., and Bo, Y. Y.: Black carbon emissions in China, Atmos. Environ., 35, 4281-4296, 2001.
Streets, D. G., Bond, T. C., Carmichael, G. R., Fernandes, S. D., Fu, Q., He, D., Klimont, Z., Nelson, S. M., Tsai, N. Y., Wang, M. Q., Woo, J. H., and Yarber, K. F.: An inventory of gaseous and primary aerosol emissions in Asia in the year 2000, J. Geophys. Res.-Atmos., 108, 1099, doi:10.1029/2003GB002040, 2003a.

Streets, D. G., Yarber, K. F., Woo, J. H., and Carmichael, G. R.: Biomass burning in Asia: Annual and seasonal estimates and atmospheric emissions, Global Biogeochem. Cy., 17, $2003 \mathrm{~b}$.

Streets, D. G., Bond, T. C., Lee, T., and Jang, C.: On the future of carbonaceous aerosol emissions, J. Geophys. Res.-Atmos., 109, D24212, doi:10.1029/2004JD004902, 2004.

Streets, D. G., Yu, C., Wu, Y., Chin, M., Zhao, Z., Hayasaka, T., and Shi, G.: Aerosol trends over China, 1980-2000, Atmos. Res., 88, 174-182, 2008.

Swart, R.: A good climate for clean air: Linkages between climate change and air pollution - An editorial essay, Clim. Change, 66, 263-269, 2004.

Tian, X. R., Shu, L. F., and Wang, M. Y.: Direct Carbon Emissions from Chinese Forest Fires, 1991-2000, Fire Safety Sci., 12, 6$10,2003$.

Turn, S. Q., Jenkins, B. M., Chow, J. C., Pritchett, L. C., Campbell, D., Cahill, T., and Whalen, S. A.: Elemental characterization of particulate matter emitted from biomass burning: Wind tunnel derived source profiles for herbaceous and wood fuels, J. Geophys. Res.-Atmos., 102, 3683-3699, 1997.

Wang, S. X. and Zhang, C. Y.: Spatial and temporal distribution of air pollutant emissions from open burning of crop residues in China, Sci. Pap. Online, 3, 329-333, 2008.

Zhang, J. F., Mauzerall, D. L., Zhu, T., Liang, S., Ezzati, M., and Remais, J. V.: Environmental health in China: progress towards clean air and safe water, Lancet, 375, 1110-1119, 2010.

Zhang, Q., Streets, D. G., He, K. B., and Klimont, Z.: Major components of China's anthropogenic primary particulate emissions, Environ. Res. Lett., 2, 045027, doi:10.1088/17489326/2/4/045027, 2007.

Zhang, Q., Streets, D. G., Carmichael, G. R., He, K. B., Huo, H., Kannari, A., Klimont, Z., Park, I. S., Reddy, S., Fu, J. S., Chen, D., Duan, L., Lei, Y., Wang, L. T., and Yao, Z. L.: Asian emissions in 2006 for the NASA INTEX-B mission, Atmos. Chem. Phys., 9, 5131-5153, doi:10.5194/acp-9-5131-2009, 2009.

Zhao, Y., Nielsen, C. P., Lei, Y., McElroy, M. B., and Hao, J.: Quantifying the uncertainties of a bottom-up emission inventory of anthropogenic atmospheric pollutants in China, Atmos. Chem. Phys., 11, 2295-2308, doi:10.5194/acp-11-2295-2011, 2011.

Zhi, G. R., Chen, Y. J., Feng, Y. L., Xiong, S. C., Li, J., Zhang, G., Sheng, G. Y., and Fu, J.: Emission characteristics of carbonaceous particles from various residential coal-stoves in China, Environ. Sci. Technol., 42, 3310-3315, 2008.

Zhi, G. R., Peng, C. H., Chen, Y. J., Liu, D. Y., Sheng, G. Y., and Fu, J. M.: Deployment of Coal Briquettes and Improved Stoves: Possibly an Option for both Environment and Climate, Environ. Sci. Technol., 43, 5586-5591, 2009. 